\title{
Caries levels among autistic children in Khartoum State, Sudan. A step towards improving the well-being of less fortunate children
}

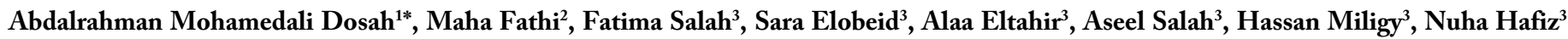 \\ and Riham Abdulrahim ${ }^{3}$ \\ ${ }^{1}$ Kingdom of Saudi Arabia Armed Forces Hospital, KSA \\ ${ }^{2}$ University of Africa, South Africa \\ ${ }^{3}$ University of Medical Science and Technology, Sudan
}

\begin{abstract}
Objectives: To determine caries levels among autistic children and compare it to that of non-autistic children.

Methodology: It is a cross-sectional comparative study; that compared autistic and non-autistic children. The data was collected from autism centers and private schools in Khartoum, Bahri and Omdurman. With sample size of 132, 44 autistic children, 88 non autistic children. Data was collected using interviews of the children's parents/guardian and oral clinical examination to assess dental caries using the Decayed-Missed-Filled Teeth index (DMFT).

Results: The prevalence of caries in the autistic group was 23(72.7\%) and that of the non-autistic group was 73(83.0\%). The mean DMFT of the non-autistic group was higher than that of the autistic group, 4.59 and 3.09 respectively. The difference between the two groups was significant ( $\mathrm{p}=0.018$ ).

Conclusion: The results of our study showed that the mean DMFT among autistic group was significantly lower than that of the non-autistic group. We suggest that this may be due to the lower sweet intake, more help received with teeth brushing and dental insurance among the autistic group. There was no significant difference in the prevalence and severity of dental caries among the autistic and non-autistic group.
\end{abstract}

\section{Introduction}

Autism is a neurodevelopment disorder which emerged as a major public health concern in the past decade in many countries. It is a lifelong disorder that begins in early childhood, first described by Kanner in 1943 [1]. Overt symptoms gradually begin after the age of six months, become established by age two or three years [2], and tend to continue through adulthood, although often in more muted form. It is distinguished not by a single symptom, but by a characteristic triad of symptoms: impairments in social interaction and communication; and restricted interests and repetitive behaviour [3]. Clinicians and researchers use the term Autism Spectrum Disorder (ASD) rather than autism. Autism is a complex disorder and researcher's still debate whether the disorder is due to genetic defects, environmental factors or combinations of both [4-6].

Epidemiologic studies from the early 1990s estimated that one in 1,500 children had autism. In 2002, this number was one in 150 [7]. More recently, the Centers for Disease Control and Prevention reported the prevalence as 5.5-5.7 per 1,000 [8]. Prevalence rates are significantly higher today than in the past.

ASDs, similar to other neurodevelopment disabilities, are generally not "curable," and chronic management is required [9], and because of their special care needs, daily care of autistic children is different from that of children with normal abilities. There is shortage of knowledge when dealing with dental conditions of children with $\mathrm{AD}$ and most of the research conducted on them is in developed countries [10].
There appear to be no known autism specific oral manifestations. Oral problems may arise because of autism related behaviors. Questions around dental caries rates among $\mathrm{AD}$ patients and the relation between them and rates of non-autistic patient are yet to be answered. Some studies indicate that $\mathrm{AD}$ as a behavioral problem should not be overlooked when considering risk for dental caries. Others claimed that using sweets as reward may affect their caries rates [11].

Desai et al., [12] reported that dental caries rates were higher in autistic children than others, whereas De Moor and Martens [13], Fahlvik et al., [14] and Shapira et al. [15] all reported that there were no differences overall in dental caries levels between autistic and nonautistic children. Shapira et al. [15] did find that older autistic people had lower DMFT values than non-autistic individuals of the same age [15].

Namal et al. found that a child without AD had 3.99 times the odds of having any experience of caries than autistics $(P=0.004, \mathrm{OR}=3.99$, 95\% CI for OR=1.56-10.19) [16].

Correspondence to: Dosah AM, Dentist, Kingdom of Saudi Arabia Armed Forces Hospital Wadi Aldwasir 11991 PO Box 338, Kingdom of Saudi Arabia, Tel: 00966580601972;E-mail: dousa4ever@gmail.com

Key words: dental caries, autistic, non-autistic

Received: November 08, 2015; Accepted: December 24, 2015; Published: December 29, 2015 
Past research efforts were targeting the enhancement of oral health among the general population. Though many factors influence an individual's dental health, there is not enough evidence to show whether $\mathrm{AD}$ is a risk factor for caries and poor oral health. There are relatively few studies that are concerned with dental status and risk factors for caries in children with $\mathrm{AD}$, and most of these studies were found in developed countries, with varying results. Our objectives are to determine caries levels among autistic children and compare it to that of non-autistic children.

\section{Methodology}

A cross-sectional comparative study that compared autistic and non-autistic children. The data of autistic children was collected from autism centers in Khartoum, Bahri and Omdurman. While for the nonautistic children data was collected from Private schools in the same study area. The inclusion criteria for the selection of autistic children was children with autism between the age of 3-16 years, excluding any autistic child $<3$ years and $>16$ years, also excluding any autistic child taking medication and those with other systemic diseases Such as epilepsy. The non-autistic group was matched for age, gender and area of residence with the autistic group. Any non-autistic child whose age was $<3$ years and $>16$ years, not attending a private school, taking medications or suffering from systemic disease was excluded.

Total coverage was used for the autistic children group and quota sampling technique was used for non-autistic children group. The sample size was 132, with 44 autistic children and 88 non-autistic children The sample was distributed as follows; 25 autistic children and 50 non autistic children from Khartoum (55.5\%), 16 autistic children and 32 non autistic children from Bahri (35.5\%) and 4 autistic children and 8 non autistic children from Omdurman (9\%).

For both groups data was collected using oral clinical examination and interviews of the children's parents/ guardian.

Regarding the interviews; the children's parents/guardian were asked to participate in the study by answering questions asked by the researcher from a questionnaire. The following areas were covered in the questionnaire: demographic information such as child's age (classified into primary dentition (3-6 yrs), mixed dentition (7-12 yrs) and permanent dentition (13-16 yrs), gender and age of parents, educational level and occupational status of parents, time of joining the centre (for the autistic children only), dental health practices which included frequency of tooth brushing, type of tooth brush and tooth paste used, person responsible for brushing the child's teeth, dietary habits included frequency of sweet consumption, frequency of giving sweets as a reward. Frequency of dental visit and dental insurance were covered.

Oral clinical examination was done to assess dental caries using the Decayed-Missed-Filled Teeth index (DMFT), WHO criteria for caries detection was used [17]. The DMFT was recorded after examining all the teeth. The examination was carried out in classrooms using examination sets and torches.

The statistical analysis was performed using SPSS software (version11). All analyses were set at $95 \%$ confidence level with an alpha level of 0.05 .

Ethical approval was obtained from University of Medical Sciences and Technology. Approval was obtained from studied autistic centers. A written informed consent was obtained from autistic and nonautistic children's guardians.

\section{Result}

There was no significant difference between the autistic and nonautistic groups in study area $(\mathrm{p}=1.00)$, gender $(\mathrm{p}=0.891)$ and age $(\mathrm{p}=1.00)$ i.e. the two groups were comparable for these variables.

The prevalence of caries in the autistic group was $23(72.7 \%)$ and that of the non-autistic group was 73(83.0\%) (Figure 1).

The mean DMFT of the non-autistic group was higher than that of the autistic group, 4.59 and 3.09 respectively. The difference between the two groups was significant $(\mathrm{p}=0.018)$ (Figure 2).

\section{Discussion}

We conducted our cross-sectional study to generate a profile of the current DMFT among autistic individuals and to compare this profile with that of a group of unaffected individuals of the same area, age and gender. To our knowledge, this is one of few studies on the dental status of individuals with autism in Sudan.

Our study was composed of 132 individuals, 44 autistics and 88 non-autistics selected from private schools and centers in Khartoum, Bahri and Omdurman. The two groups were comparable considering study area, gender and age.

In our study $72.7 \%$ of the autistic group was caries positive and $83.9 \%$ of the non-autistic group. There was no significant difference between the two groups $(\mathrm{p}=0.170)$. This is comparable with many other studies, such as those provided by Lowe et al. [18], Kopel et al. [19] and DeMattei et al. [20] while the results of Cheen Y. Loo et al. [21], Kamen et al. [22] and Namal et al. [16] found that the caries prevalence in autistic patients was lower than in non-autistic patients and in contrast Desai et al. [12] found that children with autism had higher levels of dental caries when compared to non-autistic children.

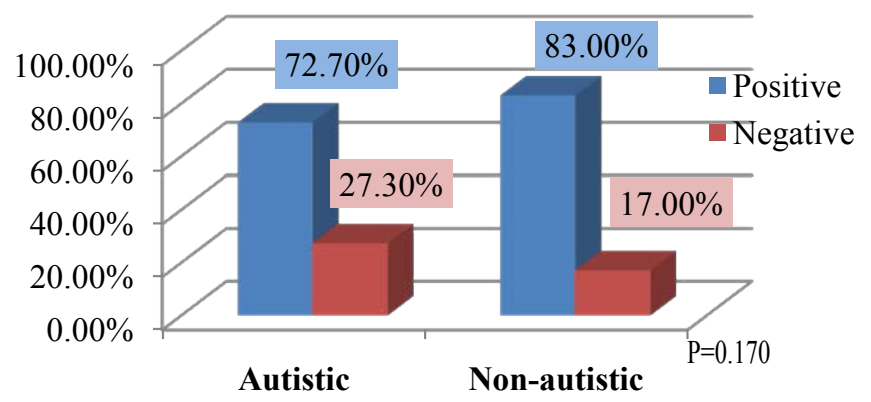

Figure 1. Prevalence of caries.

\section{Mean DMFT}

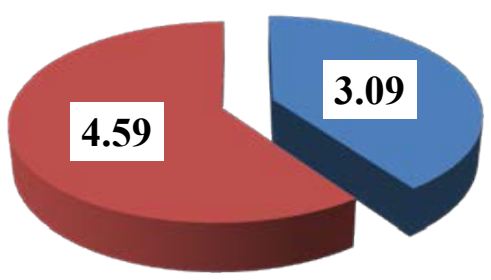

\author{
Autistic \\ - Non-autistic \\ $\mathrm{P}=0.018$
}

Figure 2. Mean DMFT. 


\section{$\square$ Yes $\square$}

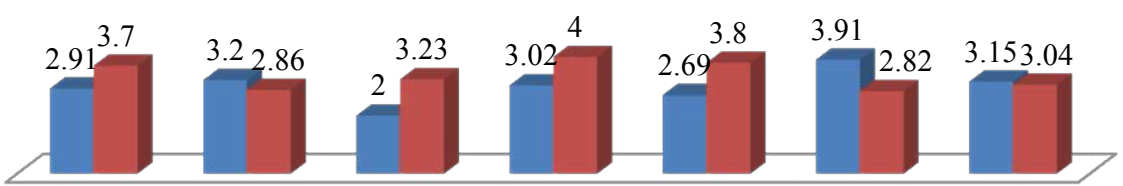

\begin{tabular}{|c|c|c|c|c|c|}
\hline $\begin{array}{l}\text { Sweet } \\
\text { intake }\end{array}$ & $\begin{array}{c}\text { Fizzy } \\
\text { Drinks }\end{array}$ & $\begin{array}{c}\text { Sweet } \\
\text { Rewards }\end{array}$ & Brushing & $\begin{array}{l}\text { Reciving } \\
\text { help in } \\
\text { Brushing }\end{array}$ & $\begin{array}{c}\text { Dental } \\
\text { visit }\end{array}$ \\
\hline
\end{tabular}

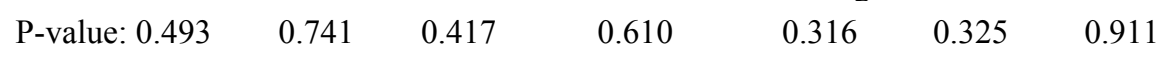

Figure 3. Mean DMFT and Independent variables among autistic group.

Table 1. Distribution of area, gender and age.

\begin{tabular}{|c|c|c|c|c|}
\hline & Autistic & Non-Autistic & Total & P-value \\
\hline $\begin{array}{l}\text { Area } \\
\text { Khartoum } \\
\text { Bahri } \\
\text { Omdurman }\end{array}$ & $\begin{array}{c}25(56.8 \%) \\
16(36.4 \%) \\
3(6.8 \%)\end{array}$ & $\begin{array}{c}50(56.8 \%) \\
32(36.4 \%) \\
6(6.8 \%)\end{array}$ & $\begin{array}{c}75(56.8 \%) \\
48(36.4 \%) \\
9(6.8 \%)\end{array}$ & 1.00 \\
\hline $\begin{array}{c}\text { Gender } \\
\text { Male } \\
\text { Female }\end{array}$ & $\begin{array}{l}32(72.7 \%) \\
12(27.3 \%)\end{array}$ & $\begin{array}{l}63(71.6 \%) \\
25(28.4 \%)\end{array}$ & $\begin{array}{l}95(72.0 \%) \\
37(28.0 \%)\end{array}$ & 0.891 \\
\hline $\begin{array}{l}\text { Age } \\
\text { Primary } \\
\text { Mixed } \\
\text { Permanent }\end{array}$ & $\begin{array}{c}11(25.0 \%) \\
29(65.9 \%) \\
4(9.1 \%)\end{array}$ & $\begin{array}{c}22(25.0 \%) \\
58(65.9 \%) \\
8(9.1 \%)\end{array}$ & $\begin{array}{c}33(25.0 \%) \\
87(65.9 \%) \\
12(9.1 \%)\end{array}$ & 1.00 \\
\hline Total & $44(100 \%)$ & $88(100 \%)$ & $132(100 \%)$ & \\
\hline
\end{tabular}

Table 2. Mean DMFT in primary and mixed/permanent dentition among autistic individuals.

\begin{tabular}{|l|c|c|c|}
\hline & Mean & Std. Deviation \\
\hline DMFT & & P-value \\
\hline Primary & 2.64 & 3.295 & 0.586 \\
Mix+permanent & 3.24 & 3.133 \\
\hline
\end{tabular}

Table 3. Frequency of brushing: sweets intake and consumption of fizzy drinks.

\begin{tabular}{|c|c|c|c|c|}
\hline & Autistic & Non-autistic & Total & P-value \\
\hline $\begin{array}{l}\text { Frequency of brushing } \\
\text { Never } \\
\text { Once a day } \\
\text { Twice a day } \\
\text { More }\end{array}$ & $\begin{array}{c}3(6.8 \%) \\
29(65.9 \%) \\
11(25.0 \%) \\
1(2.3 \%)\end{array}$ & $\begin{array}{c}2(2.3 \%) \\
49(55.7 \%) \\
36(40.9 \%) \\
1(1.1 \%)\end{array}$ & $\begin{array}{c}5(3.8 \%) \\
78(59.1 \%) \\
47(35.6 \%) \\
2(1.5 \%)\end{array}$ & 0.216 \\
\hline $\begin{array}{l}\text { Frequency of sweets intake } \\
\text { None } \\
\text { Once a day } \\
\text { Twice a day } \\
\text { Three times a day } \\
\text { More } \\
9\end{array}$ & $\begin{array}{c}10(22.7 \%) \\
13(29.5 \%) \\
13(29.5 \%) \\
3(6.8 \%) \\
4(9.1 \%) \\
1(2.3 \%)\end{array}$ & $\begin{array}{c}5(5.7 \%) \\
30(34.1 \%) \\
21(32.9 \%) \\
17(19.3 \%) \\
15(17.0 \%) \\
0(0.0 \%)\end{array}$ & $\begin{array}{l}15(11.4 \%) \\
43(32.6 \%) \\
34(25.8 \%) \\
20(15.2 \%) \\
19(14.4 \%) \\
1(0.8 \%)\end{array}$ & 0.013 \\
\hline $\begin{array}{l}\text { Frequency of fizzy drinks intake } \\
\text { None } \\
\text { Once a day } \\
\text { Twice a day } \\
\text { Three times a day } \\
\text { More }\end{array}$ & $\begin{array}{c}14(31.8 \%) \\
14(31.8 \%) \\
10(22.7 \%) \\
2(4.5 \%) \\
4(9.1 \%)\end{array}$ & $\begin{array}{c}23(26.1 \%) \\
38(43.2 \%) \\
18(20.5 \%) \\
3(3.4 \%) \\
6(6.8 \%)\end{array}$ & $\begin{array}{c}37(28.0 \%) \\
52(39.4 \%) \\
28(21.2 \%) \\
5(3.8 \%) \\
10(7.6 \%)\end{array}$ & 0.796 \\
\hline Total & $44(100.0 \%)$ & $88(100.0 \%)$ & $132(100.0 \%)$ & \\
\hline
\end{tabular}

Regarding the caries prevalence among the autistic group in the primary dentition $27.3 \%$ have caries and $18.2 \%$ don't, in the mixed dentition $68.2 \%$ have caries and $59.1 \%$ don't and among the permanent dentition $4.5 \%$ have caries and $22.7 \%$ don't and this difference was significant $\mathrm{P}$ value (0.034).

The mean DMFT of the non-autistic group was higher than that of the autistic group, 4.59 and 3.09 respectively. The difference between the two groups was significant ( $\mathrm{p}=0.018)$. This can be due to the difference in the sweets intake $(\mathrm{p}=0.013)$, parents assistance with teeth brushing $(\mathrm{p}=0.000)$ and possibly dental insurance $(\mathrm{p}=0.000)$. Other factors that may affect the difference between the two groups are frequency in brushing, tool of brushing, type of tooth brush and tooth paste used, frequency in fizzy drink consumption, using sweet as reward, but all these differences were found to be insignificant in our study. 
Table 4. Frequency of dental visits and insurances.

\begin{tabular}{|c|c|c|c|c|}
\hline & Autistic & Non-autistic & Total & P-value \\
\hline $\begin{array}{l}\text { Dental visits } \\
\text { Never } \\
\text { Once every } 3 \text { months } \\
\text { Once every } 6 \text { months } \\
\text { Once every year }\end{array}$ & $\begin{array}{l}33(75.0 \%) \\
3(6.8 \%) \\
2(4.5 \%) \\
6(13.6 \%)\end{array}$ & $\begin{array}{c}57(64.8 \%) \\
2(2.3 \%) \\
8(9.1 \%) \\
21(23.9 \%)\end{array}$ & $\begin{array}{c}90(68.2 \%) \\
5(3.8 \%) \\
10(7.6 \%) \\
27(20.5 \%)\end{array}$ & 0.226 \\
\hline Total & $44(100 \%)$ & $88(100 \%)$ & $132(100 \%)$ & \\
\hline $\begin{array}{l}\text { Dental insurances } \\
\text { Yes } \\
\text { No }\end{array}$ & $\begin{array}{l}20(45.5 \%) \\
24(54.5 \%)\end{array}$ & $\begin{array}{l}10(11.4 \%) \\
78(88.6 \%)\end{array}$ & $\begin{array}{c}30(22.7 \%) \\
102(77.3 \%)\end{array}$ & 0.000 \\
\hline Total & $44(100 \%)$ & $88(100 \%)$ & $132(100 \%)$ & \\
\hline
\end{tabular}

Table 5. Dental insurance and dental visits among the autistic group.

\begin{tabular}{|l|c|c|c|}
\hline \multirow{2}{*}{ Dental insurance } & No & Dental visits & \multirow{2}{*}{ Total } \\
\cline { 2 - 4 } & P-value & \\
\hline Yes & $12(60.0 \%)$ & $8(40.0 \%)$ & $20(100.0 \%)$ \\
No & $21(87.5 \%)$ & $3(12.5 \%)$ & $24(100.0 \%)$ \\
\hline Total & $33(75.0 \%)$ & $11(25.0 \%)$ & 0.036 \\
\hline
\end{tabular}

Table 6. Correlation between time of joining the center and DMFT.

\begin{tabular}{|c|c|c|c|}
\hline & & Time of Joining Center & DMFT \\
\hline \multirow[t]{3}{*}{ Timing of Joining Center } & Pearson Correlation & 1 & -.195 \\
\hline & Sig. (2-tailed) & - & .228 \\
\hline & $\mathrm{N}$ & 40 & 40 \\
\hline \multirow[t]{3}{*}{ DMFT } & Pearson Correlation & -.195 & 1 \\
\hline & Sig. (2-tailed) & .228 & - \\
\hline & $\mathrm{N}$ & 40 & 40 \\
\hline
\end{tabular}

When comparing the mean DMFT of the autistic and non-autistic groups in our study we found that it was lower in the autistic group. Other studies also found lower DMFT in autistic individuals $[16,15]$. However our results showed a higher mean DMFT (3.09 in the autistic group and 4.59 in non-autistic group) than in the study conducted by Namal et al. [16] (1.74 and 2.41 respectively).

There was no association found in the autistic goup between the mean DMFT and time of joining centre $(p=0.228)$, sweet intake ( $\mathrm{p}=0.493)$, fizzy drinks $(\mathrm{p}=0.741)$, frequency of brushing $(\mathrm{p}=0.610)$, dental visits $(\mathrm{p}=0.325)$, receiving help in brushing $(\mathrm{p}=0.316)$, sweet rewards $(\mathrm{p}=0.417)$, and dental insurance $(\mathrm{p}=0.911)$.

In our study the mean DMFT among the autistic group in the primary dentition was $2.64 \pm 3.295$, in the mixed dentition and permanent dentition was $2.85 \pm 2.988$. They were found to be much higher than in a study conducted by Ceyhan Altun et al. [23] were the mean DMFT in the primary dentition was $1.09 \pm 1.41$, in the mixed and permanent dentition was $0.86 \pm 1.04$.

Regarding the severity of dental caries; the percentage of the low caries levels was higher in the autistic group (73.3\%) than in the nonautistic group $(53.3 \%)$. While the percentage of the low caries was lower in the autistic group (15.6\%) when compared with the nonautistic group (31.1\%). In the moderate caries category, the percentage was lower in the autistic group (11.1\%) than in the non-autistic one (12.2\%). No one had a high caries level in the autistic group while $3.3 \%$ of the non-autistic group had a high caries level.

Our results showed that there was no significant difference between the autistic and non-autistic group in the severity of dental caries, while
Cheen Y. Loo et al. [21] found that the caries severity of autistic patients was significantly lower.

Our study showed that the majority of the autistic and non-autistic groups did not visit a dentist (75.0\%) and (64.8\%), respectively.

There was no significant difference in frequency of brushing $(\mathrm{p}=0.197)$, tool of brushing $(\mathrm{p}=0.080)$, type of brush used $(\mathrm{p}=0.467)$, type of dental paste used $(\mathrm{p}=0.199)$ among autistic and non-autistic individuals.

As many as $96.2 \%$ brushed their teeth once or more than once a day regularly which is much higher than in another study [16] were only $29.8 \%$ did. In our study the frequency of tooth brushing did not affect the dental caries level while other studies $[16,24]$ found that children who brushed their teeth irregularly had greater caries experience.

Among the autistic group $72.7 \%$ received help in brushing their teeth while $14.8 \%$ in the non-autistic group received help in brushing their teeth. This difference was significant $(\mathrm{p}=0.000)$.

There was a significant difference in the frequency of sweets intake between the two groups $p=0.013$. This may be due to the fact that the parents of autistic children control their sweet consumption.

$11.4 \%$ of the autistic group received sweet rewards and $88.6 \%$ don't, while $20.5 \%$ of the non-autistic group received sweet rewards and $79.9 \%$ don't and this difference was not significant ( $\mathrm{p}=0.194)$.

Concerning the regular dental visits, there was no significant difference between the autistic and the non-autistic groups $(\mathrm{p}=0.226)$, but when compared with the dental insurance in the autistic group, there was significant difference in the regular dental visits among those who have dental insurance (40\%) and those who don't (12.5\%) $\mathrm{p}=0.036$. 
Among the autistic group, $45.5 \%$ have dental insurance while $54.5 \%$ don't, on the other hand only $11.4 \%$ of the non-autistic group have dental insurance while $88.6 \%$ don't have dental insurance and this difference was significant $(\mathrm{p}=0.000)$.

\section{References}

1. Kanner L (1968) Autistic disturbances of affective contact. Acta Paedopsychiatr 35:100-136. [Crossref]

2. Rogers SJ (2009) What are infant siblings teaching us about autism in infancy?. Autism Res 2: 125-137. [Crossref]

3. Steyaert JG, De la Marche W (2008) What's new in autism? Eur J Pediatr 167: 10911101. [Crossref]

4. Newschaffer CJ, Croen LA, Daniels J, Giarelli E, Grether JK, et al. (2007) The epidemiology of autism spectrum disorders. Annu Rev Public Health 28: 235-258. [Crossref]

5. Geschwind DH (2009) Advances in autism. Annu Rev Med 60: 367-380. [Crossref]

6. Fombonne E (2009) Epidemiology of pervasive developmental disorders. Pediatr Res 65: 591-598. [Crossref]

7. Rice C, Schendel D, Cunniff C, Doernberg N (2004) Public health monitoring of developmental disabilities with a focus on the autism spectrum disorders. Am J Med Genet C Semin Med Genet 125: 22-27. [Crossref]

8. Centers for Disease Control and Prevention (CDC) (2006) Mental health in the United States: parental report of diagnosed autism in children aged 4-17 years- United States, 2003-2004. MMWR Morb Mortal Wkly Rep 55: 481-486.

9. Myers SM, Johnson CP (2007) Management of Children With Autism Spectrum Disorders the Council on Children With Disabilities. Pediatrics 120: 1162-1182. [Crossref]

10. Surabian SR (2001) Developmental disabilities, epilepsy, cerebral palsy and autism. $J$ Calif Dent Assoc 29: 424-432. [Crossref]

11. Broadbent JM, Ayers KM, Thomson WM (2004) Is attention deficit hyperactivity disorder a risk factor for dental caries? A case control study. Caries Res 38: 29-33. [Crossref]

12. Desai M, Messer LB, Calache H (2001) A study of the dental treatment needs of children with disabilities in Melbourne, Australia. Aust Dent J 46: 41-50. [Crossref]

13. De Moor R, Martens L (1997) Dental care in autism. Rev Belge Med Dent 52: 44-55.

14. Fahlvik-Planefeldt C, Herrstrom P (2001) Dental care of autistic children within the non-specialized Public Dental Service. Swed Dent J 25:113-118. [Crossref]

15. Shapira J, Mann J, Tamari I, Mester R, Knobler H, et al. (1989) Oral health status and dental needs of an autistic population of children and young adults. Spec Care Dentist 9: 38-41. [Crossref]

16. Namal N, Vehit HE, Koksal S (2007) Do autistic children have higher levels of caries? A cross-sectional study in Turkish children. J Indian Soc Pedod Prev Dent 25: 97-102. [Crossref]

17. WHO (1987) Oral health surveys: basic methods, $3^{\text {rd }}$ ed. World Health Organization Geneva: 334-335.

18. Lowe O, Lindemann R (1985) Assessment of the autistic patient's dental needs and ability to undergo dental examination. ASDC J Dent Child 52: 29-35. [Crossref]

19. Kopel HM (1977) The autistic child in dental practice. ASDC J Dent Child 44: $302-$ 309. [Crossref]

20. DeMattei R, Cuvo A, Maurizio S (2007) Oral assessment of children with an autism spectrum disorder. J Dent Hyg 81: 65. [Crossref]

21. Loo CY, Graham RM, Hughes CV (2008) The Caries Experience and Behavior of Dental Patients With Autism Spectrum Disorder. J.Am Dent Assoc 139: 1518-1524. [Crossref]

22. Kamen S, Skier J (1985) Dental management of the autistic child. Spec Care Dentist 5: $20-23$

23. Altun C, Guven G, Akgun OM, Akkurt MD, Basak F, et al. (2010) Oral Health Status of Disabled Individuals Attending Special Schools. Eur J Dent 4: 361-366. [Crossref]

24. Dominguez-Rojas V, Astasio-Arbiza P, Ortega-Molina P, Gordillo-Florencio E, Garcio-Nunez JA, et al. (1993) Analysis of several risk factors involved in dental caries through multiple logistic regression. Int Dent J 43: 149-156. [Crossref]

Copyright: (C2015 Dosah AM. This is an open-access article distributed under the terms of the Creative Commons Attribution License, which permits unrestricted use, distribution, and reproduction in any medium, provided the original author and source are credited. 